906 6/2

Engineering at the City and Guilds College : Prof. E. F. D. Witchelf

IN conferring the title of emeritus professor in mechanical ex ineering upon Edward Frank Dalby Witchell, th Senate of the University of London has significt s appreciation of a distinguished career in acadom cofles. His retirement severs a long and val ed connexion with the University and with the City and Guilds College. After attending the City and Guilds College during 1898-1901 as a student in the Department of Mechanical Engineering, Witchell joined the staff of the College and eventually was appointed assistant professor and reader. His election as a member of the Institution of Mechanical En. gineers and as president of the Association of University Teachers was followed by his appointment as professor in 1931, election as a fellow of the City and Guilds of London Institute in 1934 and appointment as deputy vice-chancellor of the University of London for 1945-46. His ability in debate and intimate knowledge of University procedure inevit. ably destined him to serve on the numerous academic boards, including the Board of the Faculty of Engineering, the Board of Studies in Civil and Mechanical Engineering and as its secretary for thirty-two years, the Academic Council and the Senate.

As a teacher, Witchell will long be remembered by many old students of the City and Guilds College for his clear and concise treatment of the subjects under diseussion; his apparently effortless ability to explain fundamental principles, his fund of wit and sense of humour gave to his lectures a freshness that is rarely met in lecture theatres. It is among Old Centralians, perhaps, that his versatile qualities have been most freely displayed, and no small debt of gratitude is owed to him for the part he has taken in promoting social life between students, past and present, and inspiring the loyalty and devotion to the College that is characteristic of the Old Centralians.

\section{Division of Colloid Chemistry, American Chemica Society Prof. C. Edmund Marshall}

Prof. C. Edmund Marshall, professor of soils at the University of Missouri, has been elected chairman of the Division gf Colloid Chemistry of the American Chemical Socigty, in succession to Dr. Geoffrey E. Cunningham of the Dollinger Corporation, Rochester, N.Y. Othor new officers of the Division are: Dr. Robert D. Vold (vice-chairman), of the University of Soutborn California ; Dr. W. O. Milligan (secretarytreasurer), of the Rice Institute, Houston, Texas ; Dr. W. A. Hauser, Massachusetts Institute of Technology ; Dr. M. W. Tamele, of the Shell Development Company, Emeryville, Calif.; and Dr. J. W. Williams (chairman of the Symposium Committee), of the University of Wisconsin, Madison.

Prof. Marshall was born at Bredbury, Cheshire, on January 9, 1903, graduated from the University of Manchester and received the degree of M.Sc. for work on colloid chemistry. He was awarded a threeyear research scholarship by the Ministry of Agricul. ture, and spent two years investigating the chemistry of humus at Rothamsted Experimental Station. The following year was spent in Prof. C. Wiegner's laboratory at Zurich, studying colloid chemistry and mineralogy. In 1928, he was appointed assistant lecturer in agricultural chemistry at the University of Leeds, where he started research in the colloid chemistry and mineralogy of soils and clays, which
December 21, 1946;

Vol. 158

he has continued up to the present. In 1936, Dr. Marshall was invited to become visiting associate professor of soils at the University of Missouri; he decided to remain there, and in 1941 was appointed professor of soils. He was elected president of the Soil Science Society of America this year.

\section{Tycho Brahe Celebrations}

THe Universily of Copenhagen celebrated the four hundredth anniversary on December 14 of the birth of Tycho Drahe (see Nature, December 14, p. 856), and honorary degrees were conferred on twelve astronomers from Denmark, Great Britain, Holland, Norway, Sweden, the United States and the U.S.S.R. The British representatives were Sir Harold Spencer Jones, Astronomer Royal, and Prof. F. J.M. Stratton, professor of astrophysics in the University of Cam. bridge.

\section{A Century of Chemistry in Britain}

As part of the centenary celebrations of the Chemical society, an exhibition illustrating the achievements of British chemistry during the past century and the part which chemistry plays to-day in evefyday life, organised by the Chemical Society and the Department of Scientific and Industrial Repearch, is to be held at the Science Museum, South Klonsington, during July and August 1947. The Chemical Society is preparing the first part of the exhibition, which is to be historical in character, illustrating the great advances that have taken place during the hundred years of the Society's existence. How great are those advances will be noted when it is realized that, at the foundation of the Society, Dalton's atomic theory was but thirty years old; and the study of organic chemistry was in its infancy. Each branch of chemistry is under the care of a panel of experts who are now engaged in preparing an account of the progress in the past hundred years which this exhibition serves to illustrate. The Depart ment of Seientific and Industrial Research is preparing a modern section dealing with the applications of chemistry to everyday life. Between the two parts of the exhibition there will be a linking section which will explain the processes by which the chemical engineer turns raw materials into the products which are familiar in the day-to-day life of every citizen. This will lead on to sub-sections dealing with such themes as textiles, agriculture, homes and buildings, roads and transport, fuel and power, health and food. The Department is having the co-operation of the Agricultural Research Council, various research associations and other organisations in the preparation of these exhibits; and the Central Office of Information is to be responsible for the design and layout of this part of the exhibition.

\section{Aristotle's Views on Falling Bodies}

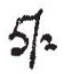

Alvaro-Alberto hes published an article (An. Acad. Brasil. Ciencjus, 18, No. 1, March 31, 1946) which em teisizegr misunderstanding regarding the teaching of $\mathrm{f}$ totle on the velocities attained by falling jodies of different masses. It is often assumed that 5 taught that the velocity was proportional to the weight of the body, and that Galileo was the first to show the falsity of this assumption. A letter from J. F. Hardcastle which appeared in Nature, 92, 584, January 22, 1914, pointed out that Aristotle was referring to motion in a resisting medium, and that the velocity which he was considering was the 


\section{No. 4025 December 2I, $1946 \quad$ N A T UR E}

terminal velocity. This velocity is attained when the force of resistance in the medium in which the body is moving is equal to the weight of the body. Greenhill had also a letter in the same issue, and in the following week Sir William Ramsay and Sir Oliver Lodge had letters which supported the point of view of Hardcastle and Greenhill. Hardeastle quotes from St. Thomas Aquinas's "Opera Omnia" (Leonine edition), which shows quite clearly that different media were considered by Aristotle-earth, air or water or other things - and if air is twice as 'subtile' as water, then for an equal distance the time of translation in water will be twice that in air. It may be added that the story, so often repeated, about Galileo dropping the weights from the Leaning Tower of Pisa close to the professors' heads as they came out from their lectures is now admitted, like some other stories about Galileo, to be apocryphal. Among these must be included the story that Galileo was the first to disprove the alleged statement of Aristotle about the velocities attained by falling bodies of different weights.

$$
36
$$

\section{Lunar Auroras}

Sky and Telescope of September contains a short note on this subject which deals with a suggestion made by Pr PA Mohd. R. Khan, Hyderabad, in Popylar Ast pnomy one. This suggestion is that aurphy honom occur on the portion of the ntoon's surface that is lighted up by earthshine, shoudd there be any appreciable atmosphere on our satellite. While it would not be possible to observe the auroral streamers, he suggests that a study of the spectrum of the earthshine on the moon might reveal the presence of the stronger of the forbidden lines of oxygen and nitrogen which are characteristic of auroras. Simultaneous spectra of neighbouring regions of the sky should also be obtained to avoid confusion between lunar and terrestrial auroral light. Prof. J. Kaplan, University of California, not only supports the suggestion but also enlarges upon it. $\mathrm{He}$ points out that direct photographs made with infra-red sensitive plates and filters would record the auroral band at $15,000 \mathrm{~A}$. due to ionized nitrogen. Variations in such photographs would reveal the presence of the aurora; they would require shorter exposure times, and would also be easier to obtain than the corresponding apetra.

\section{The New Anatomy}

Classicar afpomy, the study of visible structure for structur sake, has long since exhausted itself (and othes)! But a new generation of anatomists is shoxing us that, when morphological observations are orrelated with parallel biochemical and biophysical analyses and with considerations of function, profitable advances may result, and that, handled in this way, anatomy has still much to contribute to biological science. Prof. J. Z. Young, in his inaugural lecture as professor of anatomy at University College, London, developed this theme and put forward some stimulating suggestions for future progress in anatomical research. $\mathrm{H}_{\theta}$ deplored the rigid departmental segregation of anatomists, physiologists, biochemists, pharmacologists and so on, which so usually exists in medical schools, and urged that all should regard themselves primarily as human biologists. Each worker must necessarily practise his own specialized technique; but he should endeavour to correlate his findings with those derived from other, and often widely differing, techniques, and so view his problem from all possible angles. Prof. Young's own work on the degeneration and regeneration of nerve, in which a correlation of histological with physico-chemical findings led to an entirely new concept of the nerve fibre, is a case in point. He gives a timely warning to biologists against a too mechanistic interpretation of their subject. Living structures show an organisation or pattern on a higher level than that ordinarily regarded as physical or chemical ; consequently a purely physical or chemical approach is generally inadequate for the total handling of a biological problem.

Another fact, often overlooked in our preoccupation with seeking to relate cause and effect, is that living systems exhibit a continuous and spontaneous activity of their own, which is the very essence of being 'alive', quite apart from any response which they may make to external stimuli or experimental manipulations. This is well seen in the case of the nervous system, where the concept of reflex action, which appeals so much to the 'cause and effect' mentality, has singularly failed to account for the more important features of higher nervous activity. In this connexion Prof. Young makes the intelesting suggestion that the overall pattern of organisation of the neuropil, rather than the detailed point connexions of the individual fibres, might have some significance in the interpretation of higher nervous functions. The title of Prof. Young's address was "Patterns of Substance and Activity in the Nervous System" (London: H. K. Lewis and Co., Ltd., 1946. 1s. 6d. net). Following the tradition of his distinguished predecessors at University College, he is primarily interested in the nervous system, and he chose to illustrate his theme in that context; but the theme is applicable to all biological inquiry, and his stimulating and thoughtful address will be widely welcomed, particularly by medical men of science.

\section{Faculty of Science, Fouad I University $\quad 9$ :}

THE annual reld for 1944-45 of the Faculty of Science, Fpuad A University, Cairo, gives a brief indigationfroparch work in progress, with lists of pand puls shec and titles of theses for which degrees in s\&lice were awarded. In the Department of Applied Mathematics, R. H. Makkar has completed a thesis on "Series of Polynomials", and M. Tolba is investigating the question of two points expansion of functions, while in the Department of Applied Mathematics, Prof. M.A. Omara is engaged on determining the velocity potential of the fluid motion induced by a cylinder moving in an infinite mass of compressible fluid, and Dr. Hammad is still investigating the passage of sunlight through the atmosphere. In the Department of Physics, Prof. Fahmy has continued his work on the relativity of the electron and proton, in addition to supervising investigations on molecular polarization of vapours at different temperatures, electron polarization, electron diffraction and the viscosity of gases. Other work, under Dr. Mokhtar, has covered the scattering of supersonics, the measurement of absorption coefficients by acoustic materials and the tone qualities of musical instruments. The Meteorological Section has investigated matters connected with rainfall, sea-breezes, thunderstorms, floods in Egypt and north-east winds in the Nile Delta, while the Electronics Section has studied secondary emission, electron reflexion, X-ray analysis and Young's modulus. 